\title{
Péptidos antimicrobianos en la inmunidad innata de enfermedades infecciosas
}

\author{
Bruno Rivas-Santiago, M en C, ${ }^{(1,3)}$ Eduardo Sada, Dr, ${ }^{(1)}$ Rogelio Hernández-Pando, Dr, ${ }^{(2)}$ \\ Víctor Tsutsumi, Dr. ${ }^{(3)}$
}

Rivas-Santiago B, Sada E, Hernández-Pando R, Tsutsumi V.
Péptidos antimicrobianos en la inmunidad
innata de enfermedades infecciosas.
Salud Publica Mex 2006;48:62-7I.

\section{Resumen}

Los péptidos antimicrobianos son moléculas efectoras clave en la inmunidad innata. Generalmente contienen de 15 a 45 residuos de aminoácidos y en su gran mayoría poseen carga positiva, además de que tienen la propiedad de ser anfipáticos. Estos péptidos son secretados por células epiteliales y leucocitos, como es el caso de los macrófagos y neutrófilos. En la actualidad, con base en la traducción de secuencias en programas computacionales se han descrito más de 800 tipos de péptidos antimicrobianos distribuidos en los reinos animal y vegetal. Estos péptidos pueden ser clasificados de acuerdo con su conformación estructural y la ubicación de sus puentes disulfuro. Las defensinas constituyen uno de los tipos de péptidos antimicrobianos más estudiados, y se dividen en dos familias de acuerdo con la ubicación de sus puentes disulfuro: $\alpha$-defensinas y $\beta$-defensinas. Algunas de estas defensinas pueden ser inducidas por citocinas proinflamatorias, así como por moléculas propias de patógenos, y se ha observado que están relacionadas con la inmunopatogenia de varias enfermedades. El papel principal de los péptidos antimicrobianos es la lisis directa de microorganismos; sin embargo, a la fecha también se han descrito propiedades quimiotácticas, que le permiten modular el sistema inmune y de esta forma constituir un puente entre la inmunidad innata y la inmunidad adaptativa. Actualmente se han iniciado estudios con la posibilidad de utilizar esta clase de moléculas como nuevos fármacos en diferentes tipos de enfermedades infecciosas.

Palabras clave: péptidos antimicrobianos; defensinas; catelicidinas; inmunidad innata
Rivas-Santiago B, Sada E, Hernández-Pando R,Tsutsumi V.

Antimicrobial peptides in the innate

immunity of infectious diseases.

Salud Publica Mex 2006;48:62-7I.

\section{Abstract}

Antimicrobial peptides are key effector molecules of the innate immune response. Generally, they are formed by 14-45 aminoacid residues; most of them have a positive charge and amphipathic properties. These peptides are secreted mainly by epithelial cells, neutrophils and macrophages. Based on sequence translation using computer programs, more than 800 types of antimicrobial peptides have been described in plants and animals. Antimicrobial peptides are divided according to the position of disulfide bridges and structural conformation. Defensins are the most studied antimicrobial peptides and are classified into $\alpha$-defensins and $\beta$-defensins. Many of these defensins can be induced by proinflammatory cytokines and pathogen associated molecules. Moreover, they have been shown to partake in the immunopathology of several diseases. The main role of antimicrobial peptides is the direct lysis of microbes. These peptides also have chemotactic properties, which may modulate the immune response, serving as a bridge between the innate and adaptive immune responses. Currently, several studies are exploring the possibility of using these antimicrobial peptides as new therapeutic agents against different infectious diseases.

Key words: antimicrobial peptides; defensins; cathelicidins; innate immunity

(I) Departamento de Investigación en Microbiología, Instituto Nacional de Enfermedades Respiratorias (INER), México.

(2) Departamento de Patología Experimental. Instituto Nacional de Ciencias Médicas y de la Nutrición Salvador Zubirán (INCMNSZ), México.

(3) Departamento de Patología Experimental. Centro de Investigación y de Estudios Avanzados del IPN, México.

Fecha de recibido: 10 de febrero de 2005 - Fecha de aprobado: 28 de octubre de 2005

Solicitud de sobretiros:M en C Bruno Rivas Santiago. Instituto Nacional de Enfermedades Respiratoria. Departamento de Investigación en Microbiología. Pabellón 10. Calzada de Tlalpan 4502, 14080 México, D.F., México.

Correo electrónico: btrivas@iner.gob.mx,rondo_vm@yahoo.com 
lexander Fleming fue el primero en observar que A las secreciones respiratorias tenían poderes bactericidas. La lisosima fue la causante de esta actividad y la primera proteína antimicrobiana registrada; desde entonces se han encontrado otras proteínas y péptidos que tienen también una función antimicrobiana. ${ }^{1}$

Se considera que los péptidos antimicrobianos existen desde el inicio de la evolución de la respuesta inmune. Su amplia distribución en el reino animal y vegetal demuestra que constituyen una parte esencial de la inmunidad de los organismos multicelulares. ${ }^{2,3}$ Los péptidos antimicrobianos están presentes en plantas, insectos, animales e inclusive peces (cuadro I).

La mayoría de los péptidos antimicrobianos son moléculas catiónicas con regiones hidrofóbicas. Estas características químicas son importantes para comprender el mecanismo de acción microbicida, el cual

\begin{tabular}{|c|c|c|}
\hline \multicolumn{3}{|c|}{$\begin{array}{c}\text { Cuadro I } \\
\text { Diferentes tIPOS DE DEFENSINAS }{ }^{2}\end{array}$} \\
\hline Péptido & Origen & Tejido* \\
\hline Cecropina A & Oruga & $\mathrm{E}, \mathrm{CS}, \mathrm{H}$ \\
\hline Magainina 2 & Rana & $E$ \\
\hline Dermaseptina I & Rana & $\mathrm{E}$ \\
\hline LL-37 & Humano & $\mathrm{E}, \mathrm{CS}$ \\
\hline Buforina II & Vertebrados & $\mathrm{E}$ \\
\hline Bactenecina & Vaca & CS \\
\hline Thanatina & Insectos & CS \\
\hline Brevenina IT & Rana & $\mathrm{E}$ \\
\hline Ranalexina & Rana & $\mathrm{E}$ \\
\hline Ranateurina I & Rana & $E$ \\
\hline Esculentina I & Rana & $E$ \\
\hline Taquiplesina & Moluscos & CS \\
\hline Androctonina & Escorpión & $\mathrm{H}$ \\
\hline Protegrina I & Cerdo & CS \\
\hline$\alpha$-Defensinas & Humano & $\mathrm{CS}, \mathrm{E}$ \\
\hline$\beta$-Defensinas & Humanos & $\mathrm{E}$ \\
\hline TAP & Vacas & $\mathrm{E}, \mathrm{BC}$ \\
\hline$\theta$-Defensinas & Monos & $B C$ \\
\hline Thionina & Plantas & $\mathrm{E}$ \\
\hline Drosomicina & Drosofila & $\mathrm{H}$ \\
\hline Hepcidina & Humano & Hígado \\
\hline Bac 5 & Vaca & CS \\
\hline PR-39 & Cerdo & CS \\
\hline Indolicidina & Vaca & CS \\
\hline Apidaecina & Abeja & $\mathrm{H}$ \\
\hline Pirrocoricina & Insectos & $\mathrm{H}$ \\
\hline Histatina 5 & Humano & Saliva \\
\hline
\end{tabular}

se tratará posteriormente. Además, los péptidos antimcrobianos pueden diferir en tamaño, secuencia de aminoácidos y estructura; sin embargo, todos están genéticamente codificados; es decir, un gen codifica para cada péptido específico, independientemente de que éstos puedan tener alguna modificación postranscripcional, como es el caso de las catelicidinas y las $\alpha$-defensinas. ${ }^{2-4}$ Los péptidos antimicrobianos se agrupan en familias de acuerdo con su tamaño, su estructura y la organización de los aminoácidos. En humanos, están divididos en tres familias: defensinas, catelicidinas e histaninas (figura 1). ${ }^{5}$ Existen dos características comunes en la mayoría de los péptidos antimicrobianos, sin importar su estructura o su tamaño. Primero, tienen carga positiva debido a la presencia de un gran numero de aminoácidos básicos (en su mayoría lisina y arginina), y segundo, aproximadamente $50 \%$ de los aminoácidos que los constituyen son hidrofóbicos. ${ }^{4,6}$

En esta revisión se describen los conceptos actuales sobre las principales características estructurales y funcionales de las familias de péptidos antimicrobianos más importantes, su relación con algunas condiciones patológicas, así como su uso potencial como nuevos medicamentos.

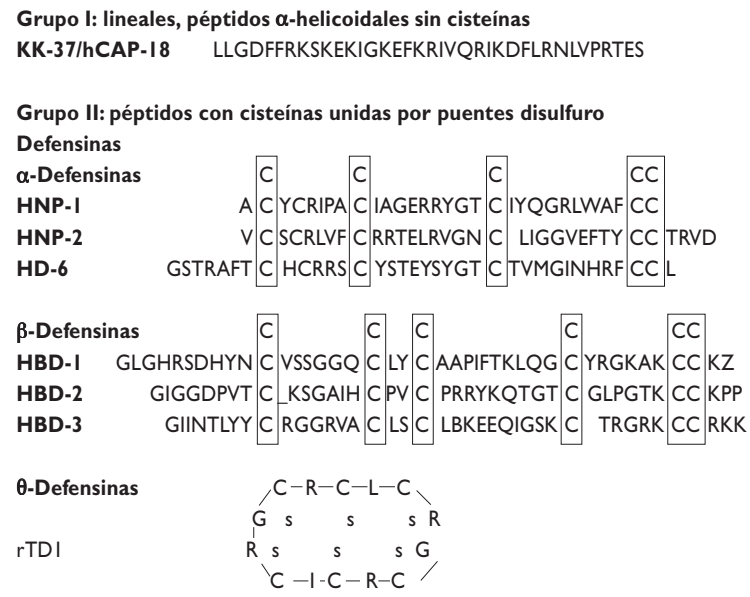

Grupo III: inusuales: alta proporción de aminoácidos específicos

PR-39 RRRPRPPYLPRPPPPPFFPPRLPPRIPPGFPPRFPRFPGKR

Histatinas

His-I DSHEEKRHHGYRRKHHSHREFPFYGDYGSNYLYDN

His-3 DSHAKRHHGYKRFHEKHHSHRGYRSNLYLYDN

Figura I. Clasificación de las defensinas 


\section{Defensinas}

Las defensinas de los mamíferos son péptidos catiónicos, relativamente ricos en arginina, con un peso molecular de 3-4.5 kDa. Contienen invariablemente seis residuos de cisteínas, los cuales están unidos entre sí por tres puentes de disulfuro, los cuales son característicos de éstas. El número de aminoácidos que conforman estos péptidos pueden variar de 20 a 45. 4,6

La familia de las defensinas se divide en: defensinas $\alpha$-, $\beta$ - y $\theta$ - y su clasificación se basa en la posición de los enlaces disulfuro. ${ }^{6-10}$ Las defensinas humanas muestran gran homología con las defensinas de otros mamíferos e insectos, así como con las toxinas del escorpión y de la anémona marina. ${ }^{6}$

En vivo, las defensinas en promedio muestran actividad antimicrobiana a concentraciones de $1-10 \mu \mathrm{g} / \mathrm{mL}$. Sin embargo, aun a concentraciones de $15-30 \mu \mathrm{g} / \mathrm{mL}$ existe actividad citotóxica. ${ }^{6}$

A continuación se describen las propiedades más importantes de cada una de las principales familias de defensinas.

$\alpha$-defensinas

Están constituidas por una cadena de 29 a 35 residuos de aminoácidos y contienen tres puentes disulfuro en las posiciones: $1-6,2-4,3-5 .{ }^{11-13}$ Las primeras $\alpha$-defensinas fueron aisladas en 1985 a partir de neutrófilos. ${ }^{11}$ Desde entonces se han identificado seis $\alpha$-defensinas. Los péptidos de neutrófilos humanos 1-4 (HNP-1 al HNP-4) están localizados en los gránulos azurófilos de los neutrófilos, en donde constituyen la principal proteína ( $60 \%$ del total) y contribuyen eficazmente en el mecanismo oxígeno-independiente para eliminar a las bacterias fagocitadas. ${ }^{14-15}$ Las otras dos $\alpha$-defensinas, 5 y 6, se encuentran principalmente en las células de Paneth en el intestino delgado y en las células epiteliales del tracto urogenital femenino., $8,10,16$

Los genes que codifican las $\alpha$-defensinas y $\beta$-defensinas están localizados en el cromosoma 8p23. El gen para HNP-2 no ha sido encontrado, lo que indica que probablemente HNP-2 es un producto proteolítico de HNP-1 y HNP-3 debido a su gran homología con respecto a la secuencia de aminoácidos. ${ }^{11}$ Las $\alpha$-defensinas son producidas como prepropéptidos y son procesadas a $\alpha$-defensinas en 4 y 24 horas. El propéptido inicial tiene 75 aminoácidos y después de su maduración está conformado por aproximadamente 56 aminoácidos. Wilson y colaboradores ${ }^{12}$ hicieron estudios en ratones a los cuales se les eliminó el gen que codifica para las defensinas HNP (ratones knockout). El resultado de este experimento fue contundente, ya que los ratones que no producían HNP fueron mucho más susceptibles a infecciones intestinales que aquellos que sí la producían.

Los microorganismos fagocitados por neutrófilos y contenidos en las vacuolas fagosomales son expuestos al contenido de los gránulos de los neutrófilos en los cuales hay una gran cantidad de defensinas. Los neutrófilos también secretan las defensinas al medio extracelular, las cuales con frecuencia son tomadas por los macrófagos para eliminar a las bacterias intracelulares. ${ }^{13,17}$

\section{$\beta$-defensinas}

En 1991 Diamond y colaboradores ${ }^{18}$ aislaron un péptido antimicrobiano a partir de lengua de vaca, al que llamaron péptido antimicrobiano traqueal (TAP). Las $\beta$-defensinas contienen seis residuos de cisteína conectados entre sí por tres puentes disulfuro, pero con espacios diferentes a los de las $\alpha$-defensinas, por lo cual los integrantes de esta nueva familia de péptidos antimicrobianos se denominaron $\beta$-defensinas. Las $\beta$-defensinas tienen de 36 a 42 residuos de aminoácidos, además de poseer puentes disulfuro en las ubicaciones 1-5, 2-4 y 3-6. Existen al menos 60 miembros de esta familia, de los cuales 43 son de mamíferos, seis de aves y 11 de reptiles y marsupiales. ${ }^{2}$

La primera $\beta$-defensina humana (HBD-1) fue aislada en grandes cantidades de hemofiltrado. ${ }^{19}$ También se expresa en el tracto genitourinario y respiratorio; sin embargo, las cantidades aisladas de HBD-1 en lavados bronquioloalveolares no demostraron que exista una cantidad significativa que actúe como microbicida. Este tipo de defensinas son secretadas de forma constitutiva y no incrementan su expresión por estímulos infecciosos o citocinas. En algunas condiciones como el embarazo se incrementa notablemente la producción de este tipo de defensina, lo que sugiere que otros factores no infecciosos pueden inducir su secreción. ${ }^{5,20}$ Existen al menos dos isoformas de $\beta$-defensinas, una de 40 y otra de 44 aminoácidos.

Las $\beta$-defensinas humanas tipo 2 (HBD-2) se encuentran en el epitelio de las superficies internas y externas del cuerpo humano, tales como la piel y el tracto respiratorio e intestinal. Algunos estudios han detectado HBD-2 en lavados bronquioloalveolares y secreciones del tracto respiratorio, ya que varias células epiteliales del pulmón son capaces de expresarla, ${ }^{20-22}$ pero necesitan de un estímulo infeccioso para ser inducidas. Sin embargo, se ha observado que existe una expresión basal mínima y que ésta se aumenta enormemente con estímulos como el ejercido por moléculas asociadas a patógenos (PAMP's) tales como lipopoli- 
sacárido, péptidoglicano, lipoarabinomanana o algunas citocinas proinflamatorias como TNF $\alpha$ e IL- $1 \beta .{ }^{23,24}$ Las concentraciones de HBD-2 que se han detectado en secreciones del tracto respiratorio están en el orden de $\mu \mathrm{g} / \mathrm{ml}$, cuando el pulmón tiene un proceso inflamatorio intenso como en el caso de la fibrosis quística; sin embargo, las cantidades basales son tan bajas que no se pueden detectar fácilmente. ${ }^{22,25} \mathrm{~A}$ la fecha sólo se ha observado un tipo de esta familia de $\beta$-defensina en los seres humanos; no obstante, O'Neil encontró que en el intestino es posible aislar un tipo diferente al de 41 aminoácidos. ${ }^{22}$

Los homólogos de la $\beta$-defensina humana en los bovinos son la TAP (tracheal antimicrobial peptide) y la LAP (lung antimicrobial peptide), las cuales se expresan después de ser inducidas por LPS (lipopolisacárido) y factor de necrosis tumoral $\alpha(\mathrm{TNF} \alpha)$, y algunos patógenos específicos de bovinos. ${ }^{23}$

Las HBD-3 al igual que las HBD-2 son inducibles por estímulos inflamatorios y pueden detectarse in vitro después de la coestimulación con IL-1 o TNF- $\alpha$. Este tipo de defensinas son un poco más grandes $(5 \mathrm{kD})$ y su mecanismo de acción es similar al de las otras defensinas. La HBD-3 se puede detectar en células epiteliales del tracto respiratorio, genitourinario, en la piel y en las amígdalas $y$, al igual que las otras $\beta$-defensinas, tienen un amplio espectro antimicrobiano. La diferencia entre las HBD-2 y la HBD-3 es que esta última tiene acción bactericida más potente in vitro y mayor actividad en contra de Staphylococcus aureus. ${ }^{24}$

Se ha informado también de la existencia de una $\beta$-defensina-4 (HBD-4), la cual tiene poder bactericida en contra de hongos y algunas bacterias, además de tener actividad quimiotáctica para monocitos. Al igual que la HBD-2 es inducible por algunas citocinas y PAMPs, la HBD-4 es inactivada por altas concentraciones de sal. La HBD-4 se ha encontrado principalmente en el tracto respiratorio, pero también se ha detectado su presencia en glándula mamaria, epidídimo, líquido seminal, útero, riñones y glándula tiroides. García refiere a esta defensina como la más potente de todas, ${ }^{26}$ sin embargo esto no se ha comprobado de forma definitiva.

Se ha encontrado que ambas defensinas, HBD-1 y HBD-2, son inactivadas por altas concentraciones de $\mathrm{NaCl}$ debido a que éste neutraliza la carga positiva de dichas defensinas, lo que podría ser importante en varias enfermedades, como es el caso de la fibrosis quística, donde las altas cantidades de $\mathrm{NaCl}$ secretadas en el pulmón inactivan a las defensinas, dando lugar a infecciones por bacterias, principalmente Pseudomonas aeruginosa. Se ha encontrado que a pesar de que en estos pacientes existe una gran cantidad de anticuerpos circulantes en contra de Pseudomonas aeruginosa, la infección se instala al estar inactivadas la HBD-2 y HBD- $1 .{ }^{27,28}$ A diferencia de la HBD-1 y la HBD-2, las altas cantidades de sal no inhiben la actividad antimicrobiana de las HBD-3. ${ }^{29}$

\section{Regulación de la expresión genética en la síntesis de las defensinas}

Debido a que las defensinas son productos del organismo con actividad microbicida que pueden controlar importantes funciones, su expresión genética está bien regulada. El gen típico de las $\beta$-defensinas está compuesto por dos exones separados por un intrón que regularmente mide $1.5 \mathrm{~kb}$. El proceso de transcripción puede variar de 300 a 400 nucleótidos en lo que se refiere al sitio de regulación de la expresión del gen. ${ }^{14}$

La expresión de las HBD-1 es constitutiva; ${ }^{23}$ en contraste, la expresión de la HBD-2 es regulada por estímulos infecciosos e inflamatorios tanto in vivo como in vitro, sin embargo, se ha observado que existe una expresión mínima de HBD-2 sin estímulo y que aumenta considerablemente después del estímulo o infección. ${ }^{27,29,30,31} \mathrm{La}$ transcripción de HBD-2 se incrementa en el tracto respiratorio durante procesos infecciosos. ${ }^{22,} 25$ En experimentos basados en cultivos celulares, la expresión de $\beta$-defensinas fue estimulada por interleucina 1 (IL1- $\alpha$, IL1- $\beta$ ), TNF $\alpha$, microorganismos (Candida albicans, bacterias Gram positivas y Gram negativas), LPS y otros glicolípidos (GL) de muchas bacterias, incluyendo de la Mycobacterium tuberculosis. ${ }^{25}$ Estos LPS interaccionan con CD14 y los receptores Toll-like (TLR) del tipo 4.

La señalización subsecuente de la unión ligandoreceptor se da por cinasas que ubiquitinan a IkBa, el cual es degradado por los proteosomas con la consecuente liberación de NF-kB, que se trasloca al núcleo, iniciando la transcripción de los genes que codifican a las defensinas. Sin embargo, es posible que existan vías alternas como la de IRF3, la cual es MyD88 independiente. Otra vía registrada por la cual se inicia la trascripción de las HBD-2 es a través de los TLR-2; en el caso de las bacterias Grampositivas y de lipoproteína sintética bacteriana, la señalización puede ser dependiente o no de CD14, lo cual lleva a la activación de la molécula adaptadora MyD88, que a su vez activa a IRAK (IL-1 Receptor Associated Kinase) y ésta a TRAF6, la que posteriormente activa a varias MAPK y finalmente fosforila a IKK ubiquinando a IKB, el cual será degradado por los proteosomas, para liberar así a NF-кB, que se transloca al núcleo, iniciando la transcripción ${ }^{26}$ (figura 2).

La presencia de los TLR4 en células efectoras importantes del sistema inmune, como los macrófagos y las células dendríticas, puede promover señales secun- 
darias que estimulan a las células epiteliales del tracto respiratorio; por ejemplo, se ha encontrado que la inducción de HBD-2 en células epiteliales del tracto respiratorio se incrementa en presencia de macrófagos alveolares. Esto puede deberse a que, como se mencionó, exista una segunda señalización dada por los macrófagos alveolares a las células epiteliales (similar al caso de presentación antigénica), o que ambas estén produciendo la HBD-2. ${ }^{25}, 32$ Se ha demostrado que la IL-1 $\beta$ incrementa notablemente la síntesis de éstas. Los LPS y GL inducen además a las citocinas y mediadores inflamatorios, incluyendo el TNF $\alpha$; estas citocinas además de atraer células inflamatorias, estimulan la liberación de defensinas por los neutrófilos. Es importante mencionar que las $\beta$-defensinas- 2 son secretadas directamente vía transGolgi y no son almacenadas en el espacio intracelular. ${ }^{33}$

Las defensinas se inducen también como respuesta al daño tisular, por lo que se pueden considerar como parte de la respuesta inflamatoria. ${ }^{10,29}$ Las defensinas tienen cuatro formas de expresión: a) específico de granulocitos, dado por la degranulación de neutrófilos, este es el caso de las $\alpha$-defensinas; b) específico de las células de Paneth, es el caso de las defensinas 5 y 6 ,

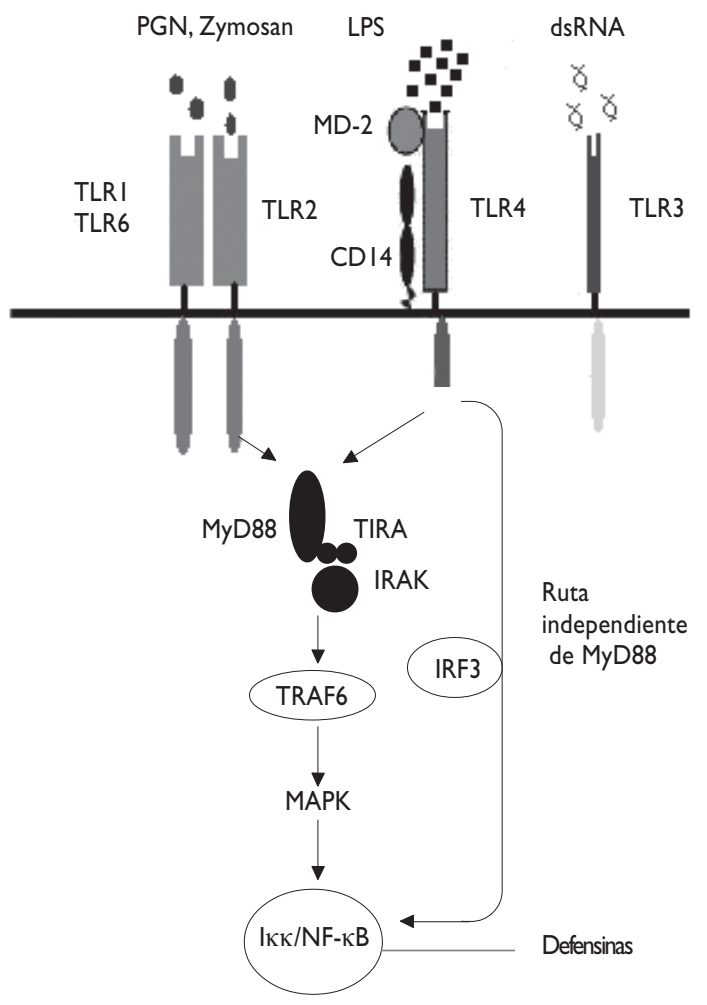

Figura 2. Señalización intracelular de los péptiDOS ANTIMICROBIANOS además de las criptidinas en el ratón, c) células epiteliales con expresión predominante en el epitelio de la lengua, traquea, tracto respiratorio, intestino delgado, colon, riñón y piel, y d) en células monocíticas del tipo fagocitario, aunque las defensinas de este origen no son específicas de este tipo de células.

Es importante mencionar que algunos estímulos como el TNF $\alpha$ inducen la expresión de HBD-2 en neumocitos tipo 2 pero no en células de Paneth, así como que el LPS estimula la expresión de este péptido en células epiteliales de tráquea, pero no en neumocitos 0 enterocitos. Por lo tanto, algunos estímulos inducen la expresión de HBD-2 en algunas células pero no en otras. ${ }^{25,32,34}$

\section{Mecanismo de acción microbicida de las defensinas}

El primer paso de la interacción entre el péptido catiónico y la membrana aniónica de un microorganismo se lleva a cabo por la atracción electrostática, la cual puede ser inhibida por grandes concentraciones de sal en la solución en la que se lleve a cabo esta interacción. El segundo paso es la permeabilización de la membrana. Este mecanismo se da por la formación de poros en la membrana debido a la incorporación de los péptidos y su organización en poros. Al final se lleva a cabo la lisis celular por choque osmótico. ${ }^{4,9,35}$

Los péptidos antimicrobianos producen exclusivamente daño en la membrana celular bacteriana, pues sólo tienen afinidad con ésta debido a que la superficie de las bacterias tiene muchos fosfolípidos con carga negativa. En contraste, la membrana externa de las células de plantas y animales está compuesta principalmente por lípidos no muy cargados, mientras que los lípidos con abundante carga eléctrica sólo se encuentran en la cara interna de la membrana. Además, la presencia de colesterol en la membrana de las células eucariontes le confiere estabilidad, reduciendo aún más la actividad de los péptidos antimicrobianos. ${ }^{2}$

La actividad antimicrobiana de las defensinas fue caracterizada en experimentos in vitro con defensinas purificadas. Los péptidos antimicrobianos, específicamente las defensinas, tienen un amplio espectro bactericida en contra de bacterias Gram positivas y Gram negativas, así como también contra virus envueltos y hongos. Las concentraciones mínimas inhibitorias se encuentran en un rango de $0.1-100 \mu \mathrm{g} / \mathrm{ml} .{ }^{36}$ Como fue detallado en las secciones anteriores, la actividad microbicida de las defensinas depende de la permeabilización de la bicapa aniónica lipídica (figura 3). Por otro lado, se ha observado que la resistencia bacteriana a los péptidos antimicrobianos es un fenómeno bastante 


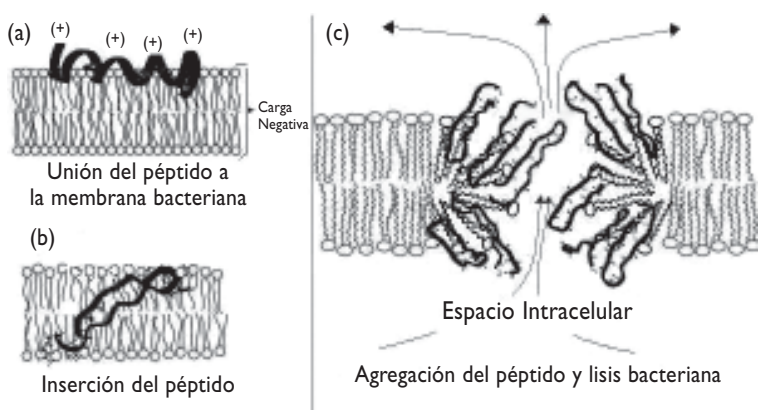

Figura 3. Mecanismos de acción de los péptidos anTIMICROBIANOS

raro. Los mecanismos de resistencia bacteriana involucran la modificación de la capa externa de la pared celular como los LPS, ácido teícoico, y fosfocolina.

Además del papel de antibióticos endógenos, los péptidos antimicrobianos tienen otras funciones en la inflamación, la cicatrización y la regulación de la respuesta inmune, ${ }^{2}$ las cuales se describen a continuación.

\section{Actividades inmunoreguladoras de las defensinas}

Por otro lado, las defensinas atraen células inflamatorias como: los neutrófilos, los linfocitos B y los macrófagos, además de que activan a estas células y a otras más, como las células epiteliales. Todas estas células liberan mediadores inflamatorios como IL-8, IFN $\gamma$, IL6, IL-10 y LTB4. Resulta interesante el hecho de que las defensinas también puedan presentar actividad antiinflamatoria por la inducción de IL-10 o SLPI. ${ }^{2,37}$

La síntesis de $\beta$-defensinas por las células epiteliales y el reclutamiento de granulocitos de sangre periférica ricos en $\alpha$-defensinas en el sitio de la inflamación genera una alta concentración de las mismas. Además de tener efecto antimicrobiano directo, las defensinas facilitan y amplifican la subsecuente respuesta inmune. En efecto, las células del bazo estimuladas con $\alpha$-defensinas humanas aumentan la producción de citocinas, así como la proliferación linfocitaria. Este mismo tipo de defensinas, cuando se administran a ratones, produce aumento sérico de IgG1, IgG2 e IgG2b. Además, pequeñas cantidades de HNP amplían la respuesta de los anticuerpos en contra de un antígeno de tumor singénico. ${ }^{38}$

El reclutamiento de células dendríticas inmaduras por defensinas pueden iniciar y facilitar la respuesta de la inmunidad adaptativa, ya que se ha demostrado que las defensinas tienen poder quimiotáctico sobre las células dendríticas inmaduras, además de que también las pueden activar. ${ }^{39}$

En relación con la actividad quimiotáctica de las células inflamatorias, tanto las quimiocinas como las defensinas habían sido estudiadas de manera separada en el pasado, hasta que se descubrió que ambas tenían funciones en común. Tanto las defensinas $\alpha$ - como $\beta$ - han sido relacionadas con funciones quimiotácticas para monocitos, células cebadas y células dendríticas inmaduras, mientras que la quimiocina LL-37 es capaz de reclutar linfocitos $\mathrm{T}$ y neutrófilos, además de monocitos. Además, se ha demostrado que las HBD-2 comparten el receptor CCR6, el cual es el receptor para la quimiocina CCL20 (LARC) que se expresa en células dendríticas y células $\mathrm{T}^{37}$ (cuadro II).

\section{Catelicidinas e histatinas}

En 1992, Zannetti descubrió en bovinos y cerdos un grupo de péptidos antimicrobianos diferente a los antes descritos, y los nombró catelicidinas, ${ }^{40}$ que actualmente se conocen con el nombre de PR-39 en cerdos y LL-37 en humanos. Estas catelicidinas son multifuncionales y tienen una clara importancia para la respuesta inmune del hospedero.

En el caso del cerdo, PR-39 es un péptido que tiene 39 aminoácidos, de los cuales $49 \%$ es prolina, $24 \%$ es arginina y sólo 5\% está conformado por otros tipos de aminoácidos. Su actividad microbicida es a través del bloqueo de la síntesis de DNA y de proteínas bacterianas. ${ }^{41}$ Se ha demostrado que PR-39 puede atravesar la membrana celular sin causarle daño aparente y posteriormente dirige su actividad microbicida afectando la síntesis de DNA y de proteínas. Se ha observado también que la presencia de PR-39 favorece notablemente la cicatrización. ${ }^{41,42}$ Actualmente varias compañías farmacéuticas están investigando esta catelicidina con fines terapéuticos.

LL-37 se origina a partir de un precursor, una molécula de $18 \mathrm{kD}$ denominada hCAP-18, la cual existe constitutivamente en los gránulos de los neutrófilos y es secretada por células epiteliales, monocitos, linfocitos T y células cebadas cuando estas células se encuentran en presencia de moléculas asociadas a patógenos. ${ }^{43}$ Además, se ha visto que las catelicidinas tienen un efecto antimicrobiano muy alto, y que al igual que las defensinas, este tipo de péptidos actúan sobre la membrana de los patógenos formando poros que llevan a la lisis del microorganismo, y además pueden actuar directamente sobre el DNA, al unirse a los grupos fosfato del DNA por uniones electrostáticas para después insertarse en la cadena de nucleótidos del DNA. Se ha observado que la inserción a la cadena del DNA 


\begin{tabular}{|c|c|c|}
\hline \multicolumn{3}{|c|}{$\begin{array}{c}\text { Cuadro II } \\
\text { Papel Quimiotáctico de las defEnsinas }\end{array}$} \\
\hline Péptido & Leucocitos a los que atrae & Receptor \\
\hline \multicolumn{3}{|c|}{$\alpha$-Defensinas } \\
\hline HNPI & Monocitos, linfocitos T, células dendríticas & No se conoce \\
\hline HNP2 & Monocitos, linfocitos T, células dendríticas & No se conoce \\
\hline \multicolumn{3}{|c|}{$\beta$-Defensinas } \\
\hline $\mathrm{HBDI}$ & Células dendríticas & CCR6 \\
\hline HBD2 & Linfocitos $\mathrm{T}$, células dendríticas, células cebadas & CCR6 \\
\hline HBD3 & Monocitos, células dendríticas & CCR6 \\
\hline HBD4 & Monolitos & No se conoce \\
\hline \multicolumn{3}{|c|}{ Catelicidinas } \\
\hline LL-37 & Neutrófilos, monocitos, linfocitos T, células cebadas & FRPLI \\
\hline
\end{tabular}

es más fuerte en la unión de los nucleótidos adeninatimina y citosina-guanina y que inhibe de esta forma la replicación del DNA. ${ }^{44}$ La quimiotáxis es otra actividad que se conoce de LL-37, principalmente sobre neutrófilos y linfocitos CD4+. ${ }^{43}$

Se ha encontrado LL-37 en líquido amniótico y semen ${ }^{45}$ algunos investigadores especulan que su presencia en el semen, además de tener acción antimicrobiana, también está involucrada en la reproducción humana, pero a la fecha no se sabe nada al respecto. Se ha observado también que LL-37 disminuye los niveles de $\mathrm{TNF} \alpha$, después de que su concentración ha sido muy elevada por la acción de LPS, lo que podría ser usado en el tratamiento de choque séptico. ${ }^{46}$

LL-37 es única en humanos y se encuentra en bajas concentraciones, por lo que es necesario producirla sintéticamente para su estudio. Debido a su estructura lineal, es relativamente fácil producirla en el laboratorio; sin embargo, debido a este tipo de estructura es también blanco fácil para las proteasas, tanto bacterianas como eucarióticas. La importancia clínica de LL-37 es evidente, especialmente su sinergismo con las $\beta$-defensinas.

Con respecto a las histatinas, existen pocas investigaciones y en su gran mayoría se enfocan a su estructura.

\section{Aplicaciones clínicas de los péptidos antimicrobianos}

El potencial terapéutico de las defensinas en enfermedades infecciosas es muy amplio. En pacientes con quemaduras graves se ha demostrado la pérdida de la capacidad de producción de defensinas en la piel afectada, por lo que en estos pacientes las infecciones recurrentes son comunes y, en ocasiones, se convierten en complicaciones mortales. Se ha observado que la aplicación de defensinas por vía tópica en estos pacientes disminuye hasta en $90 \%$ las infecciones recurrentes, además de que la aplicación de los péptidos antimicrobianos induce una mejor cicatrización debido a que algunos péptidos antimicrobianos como las $\beta$-defensinas, pero sobre todo LL-37, estimulan la proliferación de las células epiteliales además de su efecto antimicrobiano. ${ }^{34}$ Esto ha sido demostrado por Nizet y colaboradores, quienes crearon un ratón knockout para CRAMP el cual es homólogo humano para LL-37. Estos ratones fueron infectados en la piel con Streptcoccus del grupo A, y los resultados fueron contundentes. Los ratones que no producían CRAMP mostraron infección necrótica en la piel y una elevada carga bacteriana, al contrario de los ratones normales, los cuales no mostraron lesión alguna por la infección y las unidades formadoras de colonias fueron escasas. ${ }^{47}$

Estudios recientes por Uehara ${ }^{48}$ han demostrado que el Helicobacter pylori es capaz de inducir la expresión de mRNA para $\beta$-defensina-2, además de que dicha bacteria es totalmente susceptible a la acción de estos péptidos antimicrobianos. Asimismo, estos autores demuestran que las enterobacterias que contienen la isla de patogenicidad cag pueden inducir la expresión de este tipo de defensinas a través de NF-кB.

En los últimos años se han formulado hipótesis acerca de que existe un factor celular antiviral deno- 
minado CAF (por sus siglas en inglés) que se piensa que hace resistentes a algunos individuos a la infección de VIH. Esto ha dado lugar a investigaciones para la aplicación de defensinas en pacientes con infecciones virales como VIH, lo cual se encuentra en fase experimental, pero se piensa que podría ser una alternativa terapéutica importante en el futuro. ${ }^{49}$ Por otro lado, in vitro se ha registrado que algunos péptidos antimicrobianos como las retrociclinas, las cuales son defensinas, se unen a la proteínas gp120, CD4, CXCR4 y a CCR5 para bloquear la entrada del virus VIH-1 ${ }^{\mathrm{a}}$ a la célula. De la misma manera, es conocido que estas retrociclinas y las $\alpha$-defensinas tienen un efecto antimicrobiano directo sobre el viru; por lo tanto, estas defensinas actúan bloqueando la entrada del virus y eliminándolo. ${ }^{50}$ Sin embargo, todavía falta aclarar si esto es también in vivo, y de ser así, qué elementos permiten que se lleve a cabo la infección, pues podría ser que algunos individuos resistentes a la infección tengan todo este mecanismo antiretroviral bien montado, a diferencia de los más susceptibles.

El amplio espectro y la baja incidencia de resistencia bacteriana de las $\beta$-defensinas y catelicidina las sitúan como candidatas importantes para la investigación y el desarrollo de nuevos agentes antimicrobianos. Su baja toxicidad, así como la posibilidad de una administración tópica o en forma sistémica, les dan una ventaja sobre otros antibióticos.

Los autores han encontrado (datos no publicados) que las defensinas juegan un papel importante en la inmunidad innata en contra de Mycobacterium tuberculosis (MTb). Los resultados muestran que MTb induce la expresión y secreción de defensinas en el epitelio pulmonar asociándose éstas a la micobacteria, lo que ocasiona su lisis. Además, los autores han observado que las defensinas en los pulmones disminuyen las lesiones ocasionadas por MTb, lo que sugiere que estos péptidos desempeñan un papel muy importante dentro de la inmunidad en la tuberculosis. Otros investigadores han encontrado que las defensinas tienen un efecto antimicrobiano sobre MTb in vitro. $915,17,33$

\section{Conclusiones}

Hasta ahora se ha explorado muy poco acerca del papel de los péptidos antimicrobianos en la respuesta inmune de las enfermedades infecciosas; sin embargo, los estudios realizados por los autores y otros grupos en el ámbito mundial demuestran que los péptidos antimicrobianos podrían desempeñar un papel muy importante dentro de la respuesta inmune innata de muchas enfermedades infecciosas, y además, gracias a su efecto quimiotáctico, son un puente entre la inmunidad innata y la inmunidad adaptativa.

El uso con fines terapéuticos de los péptidos antimicrobianos es prometedor, ya que a pesar de haberse producido durante miles de años dentro de la inmunidad innata de los seres vivos, no se ha registrado hasta ahora un alto índice de cepas resistentes a la acción antimicrobiana de estos péptidos, lo cual puede dar lugar a la exploración de nuevas alternativas terapéuticas, sobre todo en aquellos microorganismos que son multifarmaco-resistentes y que hoy en día producen infecciones de difícil tratamiento. Es incluso posible que el uso de antibióticos tradicionales acompañados de algún péptido antimicrobiano provoque sinergia terapéutica, lo que beneficiará enormemente la eficiencia y la rapidez del tratamiento.

Desde el punto de vista epidemiológico, el estudio de la regulación genética de estos péptidos antimicrobianos nos ayudaría a identificar aquellos individuos que son susceptibles a alguna enfermedad infecciosa, ya que se sospecha que entre los individuos existe cierta susceptibilidad a algunas enfermedades, debido a polimorfismos genéticos en ciertos genes que codifican para este tipo de péptidos. Lo anterior nos podría indicar en un futuro qué poblaciones pueden ser más susceptibles a cierto tipo de enfermedades, con base en la detección de estos polimorfismos genéticos. Es posible también que debido a sus propiedades inmunomoduladoras, su uso como adyuvante en la vacunación pudiese inducir una mejor respuesta inmune celular y humoral.

El campo de los péptidos antimicrobianos aún es muy joven, faltan todavía muchas cosas por investigar para saber cómo están involucrados en la inmunpatogénesis de diferentes enfermedades, así como su posible uso terapéutico. Actualmente las líneas de investigación en esta área se van ampliando en todo el mundo; tal es el caso de algunos investigadores mexicanos que han optado por aislar péptidos antimicrobianos a partir de ranas, de insectos y de moluscos con el fin de identificar y aislar algún péptido antimicrobiano que sea óptimo para su uso terapéutico en humanos y animales. Con lo anterior se contribuiría a resolver el gran problema del costo de la síntesis a gran escala de estos péptidos antimicrobianos para el uso clínico. En este sentido, el gran reto será aislar un péptido antimicrobiano que,a pesar de provenir de otras especies, no resulte antigénico en humanos y tenga eficiencia terapéutica. 


\section{Referencias}

I. Fleming A. Antibiotic therapy, an introductory article. Med. Illus I 950; 10:477-478.

2. Zasloff M. Antimicrobial peptides of multicellular organism. Nature 2002;415:389-395.

3. Lehrer R, Lichtenstein A, Ganz T. Defensins: Antimicrobial and cytotoxic peptides of mammalian cells. Annu Rev Immunol 1993; I : 105-128.

4. Boman HG. Peptide antibiotics and their role in innate immunity. Annu Rev Immunol 1995; 13:61-92.

5. Kaiser V. Diamond G. Expression of mammalian defensin genes. J Leukoc Biol 2000;68:779-784.

6. Ganz T, Selsted ME, Szklarek D, Harwing SS, Daher K, Bainton DF et al. Defensins. Natural peptide antibiotics of human neutrophils. J Clin Invest 1985;76:1427-1435.

7. Valore EV, Park CH, Quayle AJ,Wiles KR, MCCray PB Jr, Ganz T. Human b-defensin-I: an antimicrobial peptide of urogenital tissues. J Clin Invest 1998;101:1633-1642.

8. Tang Y-Q, Vaun J, Osapay C, Tran D, Miller CA. Cyclic antimicrobial peptide produced in primate leukocytes by the ligation of two truncated a-defensins. Science 1999;286: 498-502.

9. Ogata K, Linzer BA, Zuberi RI, Ganz T, Catanzaro S. Activity of defensins of human neutrophilic granulocytes against Mycobacterium avium and Mycobacterium intracellulare. Infect immune 1992;60:4720-4725.

10. Ethan D, Stolzenberg G, Anderson M. Ephitelial antibiotic induced in states of disease. Proc Natl Acad Sci USA 1997; 16:8686-8690.

II. Selsted ME, Ganz T, Leherer RI. Primary structures of three human neutrophil defensins. J Clin Invest 1985;76: I436-1439.

12. Wilson CL, Oullette AJ, Satchel DP,Ayabe T, Lopez-Boado YS, Stratman JL. Regulation of intestinal a-defensins activation by the metalloproteinase matrylsin in innate host defense. Science 1999;286: I I3-II7.

13. Kisich K, Michael H, Diamond G, Heifets L. Tumor necrosis factor alpha stimulates killing of Mycobacterium tuberculosis by human neutrophils. Infect Immun 2002;70:459I-4599.

14. Linzmeier R, Ho CH, Ganz T.A 450-kb contig of defensins genes on human chromosome 8p23. Gene 1999;233:205-21 I.

15. Sharma S, Verma I, Khuller G. Therapeutic potential of human neutrophil peptide-I against experimental tuberculosis. Antimicrob Agents Chemother 2001;45:639-640.

16. Quayle AJ, Porter EM, Nussbaum AA, Wang YM, Brabec C. Gene expression, immunolocalization and secretion of human defensin-5 in human female reproductive tract. Am J Pathol 1998; I52:I247-I258. 17. Sharma S, Verma I, Khuller G. Antibacterial activity of human neutrophil peptide-I against Mycobacterium tuberculosis $\mathrm{H} 37 \mathrm{Rv}$ in vitro and ex vivo study. Eur Respir J 2000; 16: I I 2-1 I 7.

18. Diamond G, Zasloff M, Eck H, Brasseur M, Maloy WL, Bevins CL. Tracheal antimicrobial peptide, a cysteine-rich peptide from mamalian tracheal mucosa: peptide isolation and cloning of a cDNA. Proc Natl Acad Sci USA 1991;88:3952-3956.

19. Bensch K, Raida M, Magert H-J, Schulz-Knappe P, Forssmann WG. HBD-I: a novel b-defensin from human plasma. FEBS Lett 1995;368:331-335.

20. Singh P, Jia H,Wiles K, Hesselberth J, Liu L, Conway B et al. Production of b-defensin, by human airway epithelia. Proc Natl Acad Sci USA 1998;95: | 496|-14966.

21. Bals R, Wang X, Wu Z, Freeman, Banfa V, Zasloff M et al. HBD-2 is a salt sensitivity peptide antibiotic expressed in human lung.J Clin Invest 1998; 102:874-880

22. Hiratsuka T, Nakazato M, Date Y,Ashitani J, Minematsu T, Chino N, Matsukara $\mathrm{S}$. Identification of b-defensins -2 in respiratory tract and plasma and its increase in bacterial pneumonia. Commun. Biochem Biophys Res Commun 1998;249: 943-947.

23. O'Neil DA, Porter EM, Elawaut D, Anderson GM, Eckman L, Ganz T.

Expression and regulation of HBD-I and HBD-2 in intestinal epithelium. J Immunol 1999;163:6718-6724.

24. Harder J, Bartels J, Christophers E. Isolation and characterization of Human Beta Defensin-3, a novel human inducible peptide antibiotic. J Biol Chem 200I;276:5707-57I3.

25. Schutte B, McCray P. b-defensins in lung host defense. Annu Rev Physiol 2002;64:709-748.

26. Birchsler T, Reinhart S, Büchner K, Loeliger S, Reinhard S, Hossle P, Aguzzi A, Launer R. Human Toll-like receptor mediates induction of the antimicrobial peptide human beta-defensin 2 in response to bacterial lipoprotein. Eur J Immunol 200I;3I:3I3I-3I37.

27. Ashitani J, Mukae H, Hiratsuka T, Nakazato M, Kumamoto K,Matsukura S. Plasma and BAL fluid concentrations of antimicrobial peptides in patients with Mycobacterium avium-intracellulare infection. Chest 200I;4: II3I-II37.

28. Goldman MJ,Anderson GM, Stolzenberg ED, Kari UP, Zassloff M. Human b-defensin-I is salt-sensitive antibiotic in lung that is inactivated in cystic fibrosis. Cell 1997;4:553-560.

29. Lehrer R, Ganz T. Defensins of vertebrate animals. Curr Opin Immun 2002;14:96-102

30. Harder J, Meyer-hoffert U,Teran LM. Mucoid Pseudomonas aeruginosa, TNFa, and ILIb, but not IL-6 induce HBD-2 in respiratory epithelia. Cell Mol Biol Res 2000;22:714-72I.

31. Hiratsuka T, Nakasato M, Date Y, Minematsu T, Matsukura S. Identification of HBD-2 in respiratory tract and plasma and its increase in bacterial pnumonia. Biochem Biophys Res Comm 1998;249:943-947. 32. Bals R. Epithelial peptides in host defense against infection. Respir Res 2000; I:14|-150.

33. Kisich K, Heifets L, Higgins M,Diamond G. Antimicobacterial agent based on mRNA encoding human b-defensin-2 enables primary macrophages to restrict growth of Mycobacterium tuberculosis. Infect Immun 2002;69:2692-2699.

34. Milner S, Poindexter B, Buja M, Smith E, Bick R. Localization of human Beta-Defensin in normal and burns skin by fluorescence deconvolution microscopy. Burns 2002; I:I-4.

35. Miyakawa Y, Ratnakar P, Costello M, Catanzaro A. In vitro activity of the antimicrobial peptide human and rabbit defensins and porcine leukocyte protegrin against Mycobacterium tuberculosis. Infect Immun 1996;64:926-932.

36. Starner TD,Agerberth B, Gudmundsson GH, McCray PB Jr. Expression and activity of beta-defensins and LL-37 in the developing human lung. I Immunol 2005;3:1608-1615.

37. Durr M. and Peschel A. Chemokine Meet Defensin: the Merging Concepts of Chemoattractants and antimicrobial peptides in host defense. Infect Immun 2002;4:615-6I7.

38. Tani K, Murphy WJ, Chertov O, Salcedo R, Koh CY, Utsonomiya I et al. Defensins act as potent adjuvants that promote cellular an humoral immune responses in mice to a lymphoma idiotype and carrier antigens. Int Immunol 2002;12:691-700.

39. Yang D, Chertov O, Oppenheim JJ. Human neutrophil defensin selectevely chemoattract naive and immature dendritic cells.J Leukoc Biol 2002;68:9-14.

40. Zanetti M, Gennaro R, Romeo D. Cathelicidins: a novel protein family with a common proregion and a variable C-terminal antimicrobial domain. FEBS Lett 1995;374: I-5.

4I. Gallo RL, Ono M, Povsic T, Page C, Eriksson E, Klagsbrun M. Syndecans, cell surface heparin sulfate proteoglycans, are induced by a prolin-rich antimicrobial peptide from wounds. Proc Natl Acad Sci U SA 1994;91:11035-11039. 
42. Shi JS, Zhang G, Minton JE, Ross CR, Blecha F. PR-39, aproline-rich antibacterial peptide that inhibits phagocyteNADPH oxidase activity by binding to src homology 3 domains of p47 (phox). Proc Natl Acad Sci 1996;93:6014-6018

43. Oppenheim J, Biragyn A, Kwak L,Yang D. Roles of antimicrobial peptides such as defensins in innate and adaptative immunity. Ann Rheum Dis 2003;62:17-21.

44. Chun-Hua Hsu, Chinpan Chen, Maou-Lin Jou,Alan Yueh-Luen Lee, Yu-Ching Lin, Yi-Ping Yu et al. Structural and DNA-binding studies on the bovine antimicrobial peptide, indolicidin: evidence for multiple conformations involved in binding to membranes and DNA. Nucleic Acids Res 2005;33:4053-4064.

45. Boman GH. Antimicrobial peptides: basic facts and emerging concepts. J Intern Med 2003;254: 197-215.

46. Scott M, Davidson D, Gold M, Bowdish D, Hancock R. The human antimicrobial peptide LL-37 is a multifunctional modulator of innate immune responses. J Immunol 2002;169: 3883-3891.
47. Nizet V, Ohtake T, Lauth T, Trowbridge J, Rudisill J, Dorschner R et al. Innate antimicrobial peptide protects the skin from invasive bacterial infection. Nature 2003;4 I 4:5454-5457.

48. Uehara N, Yagihashi K, Tsuji N, Watanabe N. Human b-defensin-2 induction in Helicobacter pylori -infected gastric mucosal tissues: antimicrobial effect of overexpression.J Med Microbiol 2003;52:4I-45. 49. Zhang L, Yu W, He T,Yu J, Caffrey RE, Dalmasso EA et al. Contribution of human alpha-defensin I, 2, and 3 to the anti-HIV-I activity of CD8+ antiviral factor. Science 2002;298:995-1000.

50. Munk C, Wei G, Yang OO,Waring AJ,Wang W, Hong T et al. The theta-defensin retrocyclins inhibits HIV-I entry. AIDS Res Hum Retroviruses 2003;19:875-88| 